Transportation Research Forum

Efficiency and Effectiveness Impacts of a Computer-Assisted Scheduling and Dispatching System Implementation

Author(s): Paul Metaxatos and Anthony M. Pagano

Source: Journal of the Transportation Research Forum, Vol. 43, No. 1 (Spring 2004), pp. 77-90

Published by: Transportation Research Forum

Stable URL: http://www.trforum.org/journal

The Transportation Research Forum, founded in 1958, is an independent, nonprofit organization of transportation professionals who conduct, use, and benefit from research. Its purpose is to provide an impartial meeting ground for carriers, shippers, government officials, consultants, university researchers, suppliers, and others seeking exchange of information and ideas related to both passenger and freight transportation. More information on the Transportation Research Forum can be found on the Web at www.trforum.org. 


\section{Efficiency and Effectiveness Impacts of a Computer-Assisted Scheduling and Dispatching System Implementation}

Computer-assisted scheduling and dispatch (CASD) systems have been implemented in many paratransit systems in the United States to improve the effectiveness and efficiency of operations. This paper contributes to the limited literature of studies documenting the impact of such systems on paratransit operations based on the implementation of such a system in a small city in Illinois. The analysis provides evidence of small but measurable efficiency and effectiveness gains. This paper also provides evidence that proper CASD evaluation efforts should allow enough time after implementation so that not only familiarity with the system has been established, but also most or all of the necessary organizational changes related to the new technology have been completed.

by Paul Metaxatos and Anthony M. Pagano

Advances in technology along with federal and state transportation initiatives in the United States over the last decade have provided an impetus for paratransit operators to invest in technological upgrades. Computer-assisted scheduling and dispatch (CASD) software, in particular, has the potential to improve performance in a number of ways including increased vehicle load ratios, interagency connections, interactive voice driven reservation systems and dramatically streamlined billing operations (Kikuchi 1988, Goeddel 1996, Khattak and Hickman 1998). Yet, paratransit agencies face various financial constraints that affect their ability to purchase a CASD system and even then expectations vary (Pagano et al., 2001).

A 1999 survey identified a total of 255 deployments of CASD systems that are either operational, under implementation or planned for deployment, a 30\% increase from a 1996 count (Goeddel, 2000). Interestingly however, few studies have reported on the transition from manual to automated dispatch systems possibly because of (a) the need for the large database required to document change and (b) the lack of organizational stability in the dynamic paratransit environment. Dynamics in paratransit include high driver turnover and absenteeism rates, changes in vehicle fleet size or capacity and composition, and service area size and revenue changes. Lack of a database of previous operational information along with current reporting requirements have hindered an in-depth analysis of the agency's productivity. Additionally, because most agencies either accomplished automation incrementally or did so without public funding, few efforts were undertaken which document the before-and-after effects of automation.

This paper follows the implementation of such a system in a small city in Illinois. An evaluation of the impacts on operations discusses the experiences obtained from the particular implementation. An examination of the impacts of the system on service quality is reported elsewhere (Pagano et al., 2002).

The analysis in this paper provides evidence of small but measurable efficiency and effectiveness gains. This paper, also, provides evidence that proper CASD evaluation efforts should allow enough time after implementation so that not only familiarity with the system has been established, but also most or all of the necessary organizational changes related to the new technology have been completed. 


\section{BACKGROUND}

\section{Functions and Features of CASD Systems}

Computer-assisted scheduling and dispatching (CASD) systems can perform and integrate many transit operations. CASD scheduling of paratransit services, in particular, entails the recording and scheduling of incoming passenger reservations for on-demand, realtime trip making or for advance reservations for trips during the next day, week, or month. Passengers, vehicles, and in some cases, drivers are scheduled based upon the types of service required, time/day of week, and trip origin and/or destinations. Vehicle routes and schedules are optimized by minimizing travel time or distance subject to constraints of vehicle capacity and the passenger's desired pick-up and drop-off times.

The number of individual features available in the many versions of paratransit CASD systems can number in the hundreds, using many different names and with overlapping descriptions and functions. Lave et al. (1996) suggest five categories of software functions: reservations, scheduling, routing, dispatching and reporting. In addition, automatic vehicle location (AVL) capability is another function that can be included in a CASD system to assist in locating vehicles in real time. Many of the newest systems integrate AVL and CASD systems, allowing the using agency to enjoy the benefits of both systems.

\section{Expected Benefits of CASD Systems}

Expected traveler benefits due to these technologies include: increased paratransit reliability, reduced frustration from uncertain wait times, travel time savings, and reduced uncertainty in travel times due to improved content and quality of transit information. All combine to improve satisfaction with transit service (Khattak and Hickman 1998).

Khattak and Hickman (1998) polled transit agency staff members including general managers, boards of directors, dispatchers, telephone operators and drivers. The survey used a five point Likert scale to assess reactions to AVL/CASD implementation. In the survey, improved ability to monitor vehicle location and schedule adherence were rated the most important benefits from introducing CASD.

Other researchers (Kikuchi 1988, Stone 1994, Underwood et al. 1995, Goeddel 1996, Lave et al. 1996, and Khattak and Hickman 1998) argue that increased efficiency in paratransit operations should follow from efficient scheduling of vehicles/drivers to passenger trip requests, the validation of trip requests with provided services, and the certification of pre-approved (subsidized) fare payments. CASD systems can increase the utilization of vehicle fleets, reduce nonrevenue vehicle miles (or vehicle hours), and reduce the costs and time investment of fleet dispatching, and the recording and billing of services provided.

CASD systems may also increase customer convenience and improve paratransit service through improved response time in the request process, more accurate pick-up and drop-off times, increased flexibility of scheduling, and reduced travel times. Successful installation of CASD systems will allow the paratransit agency to comply more faithfully with both the spirit and letter of the Americans with Disabilities Act (ADA) toward safety, independence and security.

CASD systems may provide two other benefits: (1) allow a minimum level of uniformity across transit agencies and (2) track performance across dimensions of interest to paratransit managers. An additional benefit is the tracking of some performance indicators that is impossible without automation (e.g. dispatcher effectiveness, call length, and noshow rates by customer). This will allow management of previously hidden burdens on efficiency.

Two studies that have attempted CASD evaluation have produced inconclusive results. Stone et al. (2001) evaluated the WinstonSalem Mobility Manager and concluded “... ridership, productivity, and service gains 
determined by intuitive assessment of traditional measures are not supported by statistical analysis.” Kikuchi (1988) in a more limited-scope effort described the difficulties of monitoring performance and related management requirements of paratransit operation. He concluded that paratransit operations would become far more productive by integrating computer technology into daily activities of scheduling, billing and reporting.

\section{CASD SYSTEM IMPLEMENTATION}

\section{Service Area Characteristics}

The paratransit agency that implemented the CASD system has an operating area that is contained within the boundaries of the threecounty 1,800-square-mile region of Peoria, Tazewell and Woodford counties in central Illinois. The city of Peoria, Ill., is in the center of the three-county region and is located approximately 160 miles from St. Louis, 140 miles from Chicago and 200 miles from Indianapolis. The service area had a population of 346,000 in 1998.

The elderly population represents a primary customer base for the paratransit operator. Slightly greater percentages of the over age 65 population reside in the urbanized areas of the tri-county region, and each of the three counties has slightly higher percentages of elderly residents than the state of Illinois as a whole.

Although Woodford County is experiencing the greatest rate of growth, it is the most lightly populated area with only 9.4 people over the age of 65 per square mile, creating a significant obstacle to cost-effective paratransit service in that region. Both Peoria and Tazewell counties have higher densities of elderly than the state average.

The agency operated a fleet of 29 vehicles, 26 of which were wheelchair accessible. An average of 300 passengers per day were served by the organization. The total number of one-way trips provided in 1998 was 143,573 .

\section{Coordination Issues}

CASD systems are designed to support coordinated transit activities and provide the technological solution to a multi-agency brokerage (i.e., a centralized authority that utilizes transit providers to offer transit services either directly or indirectly). At the time of the study, three paratransit agencies served the study area; yet, no formal coordination existed among the three providers in the region.

\section{CASD System Description}

The agency's CASD implementation included the purchase of both hardware and software components. The computer hardware comprised one server, five workstations and a printer connected via a local area network. All hardware components were obtained from a local retail franchise and represented average hardware capabilities at the time of purchase. The server was purchased with two highcapacity hard drives and a tape back-up system. The server contained a (then) relatively fast $266 \mathrm{MHz}$ CPU, while each of the initial workstations was configured with $300 \mathrm{mhz}$ processors and single hard drives. The server and workstations were linked in a local area network (LAN) providing server and laser printer access from any connected workstation.

The organization's software package consists of a semi-customized, commercial paratransit management software package. The software was provided and installed by a major, established vendor. Although the software package installed at the study site is a relatively basic configuration, the software was upgradeable, allowing the addition of automatic vehicle location devices, mobile data terminals, and other related modules.

The installed software package is designed to store, tabulate, and report a wide range of performance measures, including odometer readings, time stamps for various legs of each trip, dispatcher and driver efficiency measures and a large number of 
passenger data elements. The CASD system calculates and reports complicated billing transactions involving multiple agencies.

More complex or ad hoc report generation capabilities are available with either the purchase of a report-writing module designed to create custom reports or by accessing the system's database directly with any of several commercial database or spreadsheet applications capable of reading standard database files.

The software package is compatible with the Windows $(\subset)$ operating system and is designed to allow a maximum of interaction with simple "point and click" mouse actions. Except for direct data entry, virtually all activities are accomplished using the computer's mouse controls.

The study site installed paratransit software designed to support all of the most common actions taken in paratransit scheduling operations. Dispatching features include automatic schedule adjustment in which real-time input of schedule changes can be made to already-issued manifests. Realtime vehicle location information allows the dispatcher to alert passengers of early and late vehicle arrivals. With regard to same-day scheduled trips, new riders can be assigned and the software automatically updates pickup and arrival times of future passengers, assigning the new rider to the trip if existing rider schedule changes are not pushed beyond the early or late arrival windows established by management.

\section{METHODOLOGY}

Transit system evaluation and the development of appropriate indicators of system performance have been in development since the inception of public transit systems, but the first national-level attempt at introducing uniform performance standards is attributed to the National Committee on Urban Transportation in 1958 (Tomazinis 1975). Tomazinis (1975) also suggested a conceptual framework that has evolved into the dimensions of efficiency, effectiveness, and quality. Pagano et al.
(1983) expanded research in quality measures. Allen and DiCesare (1976) suggested that an evaluation framework is needed and Casey and Collura (1994) proposed such a methodology.

Evaluation measures compiled from the literature (Pagano et al., 2000) for efficiency, and effectiveness are shown in Table 1. The particular site under evaluation presented challenges to data collection, verification and classification. Challenges arose with identifying seemingly simple measures as load factor and revenue hours, because preimplementation data was insufficient to support meaningful comparison with the postimplementation period. These issues are discussed in great detail elsewhere (Pagano et al., 2000).

Transit system evaluation is normally done by: peer-group analysis, arbitrary performance standards (either self-imposed or provided by governmental and other funding agencies), time-series analysis, and beforeafter analysis. The variety of demand response missions, service areas and operational configurations complicate the use of peer group analysis of paratransit operators. Moreover, difficulties with norms or standards follow first from a lack of industry-wide agreement either on which measures to use or what level of attainment of any particular measure is "average.” In addition, time-series analysis compares changes in data from the same agency over time. Clearly, time-series analysis could not be conducted here given the length of the evaluation period.

Before-and-after analysis is a special case of time-series analysis. The difference is that a before-and-after analysis is predicated on some major event affecting the organization as a whole. The installation of a CASD system is the obvious application of the before-andafter analysis because the full range of performance measures in the pre-installation period is compared to the same performance measures from the post automation period.

On the other hand, a with-and-without analysis is a common management technique that filters out changes that are not directly related to the CASD implementation. In 
essence, a with-and-without analysis would show what the results would be with the CASD vis-à-vis without the CASD, attempting to hold other factors and variables constant.

In this paper, the measurement of efficiency and effectiveness impacts has been conducted by a before-and-after-analysis as well as a with-and-without analysis. The former method is typically used in evaluations of intelligent transportation systems. The difficulty with this approach is that the collection of reliable data and construction of appropriate data sets from the before-and-after periods becomes problematic because the evaluation effort is usually undertaken well before the learning curve has been stabilized or organizational changes (due to system implementation) have taken place. In such cases, a with-and-without analysis could complement the evaluation effort because it is not affected by the problems afflicting a before-and-after analysis.

\section{Efficiency and Effectiveness Evaluation Measures Used}

One definition of efficiency is "...how well a system is using its resources to provide transit services. [It is] the ratio of output (e.g., level of service provided) to input (e.g., cost or resource usage), that is, providing the desired result with a minimum of effort, expense, waste, and so on (doing things right)" (Urban Public Transportation Glossary 1989).

A list of efficiency measures used in this paper is shown in Table 1. The first nine efficiency measures can be used to monitor the level of resource input in regards to financial performance. Efficiency measures 10 and 11 in Table 1 are general indicators measuring how economically a system is providing service. Here, "Total Expenses" means total operating expenses (operating and administrative) for the entire system, but excluding capital purchase expenses. In addition, "Vehicle Miles” equals all mileage, including deadhead (moving a revenue vehicle in other than revenue service). Finally, "Vehicle Hours" equals all vehicle time, including deadhead.

Efficiency measure 12 indicates the efficiency with which service is delivered and the market demands for the service. Measure 13 indicates the efficiency with which service is delivered, while measure 14 reflects the level of service provided. Measure 15 indicates the amount of output for each dollar of expense. This is the opposite of the more familiar cost per vehicle mile. Finally, measure 16 is an indicator of vehicle utilization.

Table 1: Efficiency and Effectiveness Measures Used

\begin{tabular}{|l|l|}
\hline \multicolumn{2}{|c|}{ Efficiency Measures } \\
\hline 1. Administrative Salaries/Peak Vehicles & 9. Total Expenses/One-Way Passenger Trips \\
\hline 2. Administrative Salaries/Vehicle Hours & 10. Total Expenses/Vehicle Hours \\
\hline 3. Administrative Salaries/One-way Passenger Trips & 11. Total Expenses/Vehicle Miles \\
\hline 4. Administrative Salaries/Vehicle Miles & 12. Total Salaries/One-Way Passenger Trip \\
\hline 5. Dispatch Salaries/Vehicle Hours & 13. Total Salaries/Vehicle Miles \\
\hline 6. Dispatch Salaries/Vehicle Miles & 14. Vehicle Miles/One-Way Passenger Trips \\
\hline 7. Driver Salaries/Vehicle Hours & 15. Vehicle-Miles/Total Expenses \\
\hline 8. Driver Salaries/Vehicle Miles & 16. Vehicle Hours/Vehicle \\
\hline \multicolumn{2}{|c|}{ Effectiveness Measures } \\
\hline 1. Administrative Salaries/Passenger Hours & 6. Total Expenses/ One-way Passenger Trips \\
\hline 2. Administrative Salary/One-way Passenger Trips & 7. Total Salaries/ Passenger Hours \\
\hline 3. Dispatch Salaries/ Passenger Hours & 8. One-way Passenger Trips/Employees \\
\hline 4. Driver Salary/Passenger Hours & 9. One-Way Passenger Trips/Vehicle Hours \\
\hline 5. Passenger Ride-Time & 10. Vehicle Miles/One-way Passenger Trips \\
\hline
\end{tabular}

Source: Pagano et al., 2000. 
Effectiveness is "...the use of output to accomplish goals, or the benefit the public actually receives from the service. [It is] the correspondence of provided service to intended output or objectives, particularly the character and location of service; in other words, producing the intended result (doing the right things). Also, the degree to which the desired level of service is being provided to meet stated goals and objectives ...” (Urban Public Transportation Glossary 1989).

The effectiveness measures used in this study are shown in Table 1. Measures 1 to 7 provide a sense of how inputs are related to system outputs. The lower the ratio, the better the system is distributing its outputs. Measure 8 is an indicator of overall labor productivity. Measure 9 tracks how successfully the system is providing its product and how well the supply and demand for service are matched to each other. Finally, measure 10 is an indicator for system accessibility that is influenced by the level of demand and the supply of service provided.

\section{Implementation Phases}

The study investigated changes during three pre-defined periods. The pre and postimplementation periods were designed to encompass equal six-month time increments. The implementation period was defined so as to begin after all manual dispatching activities had ceased and the CASD was used to accomplish as much of the day-to-day activities as possible. Pre-implementation activities included customer data entry, geocoding, sponsor code assignment, training, system shakeout, and hardware/support systems installation.

\section{DATA ISSUES}

The study site presented challenges to data collection, verification, and classification that were well documented in Pagano et al. (2000).
With regard to financial data in Table 2, all variables are monthly averages of each sixmonth implementation period. The postimplementation data were adjusted for changes in the Consumer Price Index and for additional personnel that were unrelated to the implementation of the CASD. The following points provide some details about the financial data collected:

- Administrative salaries include only those salary expenses directly related to staff not performing driving, maintenance or dispatch/scheduler duties.

- Driver salaries include only those costs of paying permanently assigned drivers (full and part-time), excluding the salaries of dispatchers who occasionally provide driver support. Dispatcher salaries include only those expenses paid to personnel filling permanent dispatch/ scheduler positions, excluding the occasions when drivers may substitute for or augment dispatcher/schedulers. Salary changes were not linked with any organizational or procedural changes resulting from implementation of the CASD.

- Maintenance salaries were increased by the addition of both a part-time and fulltime employee in the postimplementation period. The additional maintenance cost is not related to installation of the CASD.

- Total salary includes only direct salary expenses excluding Federal Insurance Contributions Act (FICA) and associated salary/wage costs.

- Other costs include non-vehicle insurance, depreciation, and worker's compensation, none of which are affected directly or indirectly by CASD installation.

- Total costs include depreciation, rent, and legal fees in addition to the major categories listed above. 
CASD Systems

Table 2: Average Monthly Financial Variables (before-after analysis)

\begin{tabular}{lcccc}
\hline $\begin{array}{c}\text { Category } \\
\text { Average Monthly) }\end{array}$ & $\begin{array}{c}\text { Pre } \\
\text { (Avg. Monthly) }\end{array}$ & $\begin{array}{c}\text { Post } \\
\text { (Avg. Monthly) }\end{array}$ & $\begin{array}{c}\text { Avg. Monthly Post-Imp } \\
\text { (Less CPI and Adt'l Pers) }\end{array}$ & $\begin{array}{c}\text { Pre to Post } \\
\text { Adj. \% } \\
\text { Change** }\end{array}$ \\
\hline Administrative Salary & $\$ 10,246$ & $\$ 11,780$ & $\$ 10,244$ & $0.0 \%$ \\
\hline Driver Salary & $\$ 36,876$ & $\$ 38,094$ & $\$ 37,280$ & $1.1 \%$ \\
\hline Dispatch Salary & $\$ 8,692$ & $\$ 8,554$ & $\$ 8,372$ & $-3.7 \%$ \\
\hline Maintenance Salary & $\$ 1,930$ & $\$ 2,979$ & $\$ 1,975$ & $2.3 \%$ \\
\hline Total Salary & $\$ 57,744$ & $\$ 61,407$ & $\$ 57,871$ & $0.2 \%$ \\
\hline Operating Expenses* & $\$ 23,761$ & $\$ 23,644$ & $\$ 23,139$ & $-3.0 \%$ \\
\hline Other Costs & $\$ 18,634$ & $\$ 22,888$ & $\$ 22,399$ & $20.21 \%$ \\
\hline Total Costs & $\$ 100,139$ & $\$ 107,939$ & $\$ 103,409$ & $3.27 \%$ \\
\hline
\end{tabular}

Source: Pagano et al., 2000. * Operating Expenses $=$ Fuel and Lubricants, Vehicle Insurance, and Vehicle Maintenance (Only); ** All adjusted financial data reflects a reduction of $2.1348 \%$ CPI and appropriate reductions of increases due to additional personnel not associated with CASD implementation.

Non-financial variables in Table 3 include employee counts, passenger hours, one-way passenger trips, peak vehicles, and vehicle hours/miles. All figures in Table 3 are monthly averages of two-month periods from each of the implementation periods except peak vehicles which is the average maximum number of vehicles dispatched during weekday periods (see Pagano et al., 2000). Pre-implementation system performance data is an average of March and June 1998; postimplementation data is an average of September and November 1999. These months were chosen to provide both a winter weather and non-winter weather month in each period. added to assist in run posting (recording arrival and departure times, mileage and passenger counts in the CASD database), augmenting permanent staff when needed. The maintenance personnel were added to assist an already over-taxed maintenance staff. No direct or indirect CASD influences were observed in the operations manager or maintenance personnel additions. The parttime run-posting position is a direct result of CASD implementation, reflecting the added task of updating the CASD database with every passenger manifest. CASD operations require run-posting activities to update projected database arrival/departure times, passenger loading, no-shows, etc.

Table 3: Average Monthly Weekday Non-Financial Measures (before-after analysis)

\begin{tabular}{|c|c|c|c|c|}
\hline $\begin{array}{c}\text { Category } \\
\text { (Average Monthly Mon. - Fri) }\end{array}$ & $\begin{array}{c}\text { Pre } \\
(\text { Avg. Mo.) }\end{array}$ & $\begin{array}{c}\text { Post } \\
(\text { Avg. Mo.) }\end{array}$ & $\begin{array}{c}\text { Post Adjusted } \\
\text { (Avg. Monthly less- } \\
\text { Adt'l Pers) }\end{array}$ & $\begin{array}{c}\text { Pre to Post } \\
\text { Adj. } \\
\text { \% Change }\end{array}$ \\
\hline Employees & 34 & 37 & 34.5 & $1.5 \%$ \\
\hline Passenger Hours & 8,334 & 8,026 & - & $-3.7 \%$ \\
\hline One-Way Passenger Trips & 11,793 & 11,021 & - & $-6.5 \%$ \\
\hline Peak Vehicles (Avg. Weekday) & 20 & 20 & - & $0.0 \%$ \\
\hline Vehicle Hours & 3,287 & 3,188 & - & $-3.01 \%$ \\
\hline Vehicle Miles & 42,498 & 39,532 & - & $-6.97 \%$ \\
\hline
\end{tabular}

Source: Pagano et al., 2000.

The number of employees is the average employee count in each implementation period. Pre- and post-implementation employee levels changed with the addition of a full-time operations manager, and one fulltime and one part-time maintenance employee. One additional part-time employee has been
In addition, the following points clarify some measurement issues in Table 3:

- Passenger hours were calculated as the product of passenger trips and $m$ e a $n$ passenger ride time.

- One-way passenger trips is a count of oneway weekday trips. Holidays falling on 
weekdays have been excluded as have days where significant weather events seriously degraded performance.

- Peak vehicles are an average count of vehicles dispatched during the busiest part of the day. Fleet peak numbers are affected by the service area's local work schedules, as a significant proportion of the agency's passenger trips transport riders to work sites.

- Vehicle hours is the difference between reported last passenger drop-off and reported first passenger pick-up times on the manifest.

- Vehicle miles is a monthly average of all odometer miles reported on the passenger manifest during each implementation period.

\section{EMPIRICAL RESULTS}

\section{Changes in Financial and Non-Financial Indicators}

The following observations can be made from Table 2 in regard to financial indicators changes between the pre- and postimplementation periods:

- After salary and CPI adjustments, administrative salary remained essentially unchanged between the pre- and postimplementation periods.

- The slight increase in driver salaries despite reduced miles and vehicle hours seems to reflect additional overtime of those drivers who extended their working days to cover routes for absent drivers.

- Adjusted average total salary remains essentially unchanged over the pre- and post-implementation periods, increasing only $0.22 \%$.

- Operating expenses fell by $3 \%$ in real terms from $\$ 23,761$ to $\$ 23,139$ per month. The decrease in operating costs was due to a decrease in vehicle miles and hours, lower fuel prices, and a reduction in total passengers in the postimplementation period.
- Of the cost categories included in other costs, salary related expenses and specifically, worker's compensation has contributed most to pre- and postimplementation change, adding an average change of nearly $\$ 5,000$.

- Dispatch salaries, operating costs and other costs show the greatest change, however none of these changes can be directly connected to CASD implementation.

The following points can be made regarding non-financial indicator changes in Table 3:

- Calculated average monthly passenger hours decreased $3.7 \%$ in the post implementation period to 8,026 , following a slight increase in passenger ride time and a decrease in the number of passenger trips.

- Total one-way passenger trips dropped from 11,793 reported in the preimplementation period to 11,021 in the post-implementation period. This $6.5 \%$ reduction reflects changes in contract service agreements between the agency and its agency clients rather than any influence of CASD implementation.

- Peak vehicle data fluctuates within a narrow range because of contractual prohibitions limiting the use of some vehicles, reducing the potential optimization of those vehicle assets.

- Vehicle hours decreased by approximately $3 \%$, likely driven by the reduction in ridership described above. Vehicle hours were also likely influenced by demographic changes in the ridership base due to service contract changes (riders living in more rural areas or having more severe disabilities require longer ride or loading times).

- Vehicle miles (difference between last passenger drop-off and first passenger pick-up odometer readings) decreased nearly $7 \%$, due to the change in ridership volume and demographics associated with changing contracts with the service agencies. 


\section{Before-and-After Efficiency Analysis}

The analysis compares a number of relevant expense categories with fleet size changes, average fleet hours, miles, and one-way passenger trips. Table 4 displays pre and postimplementation comparisons of measures used in this study.
Efficiency measures per average monthly vehicle mile in Table 4 illustrate the effect of a reduction in fleet vehicle miles. Although dispatch salaries fell, and other salaries changed only slightly between evaluation phases (Table 2), the decrease in recorded mileage (Table 3 ) resulted in positive changes in most efficiency measures (Table 4). A 1.5\%

Table 4: Average Monthly Efficiency Measures Matrix (before-after analysis)

\begin{tabular}{lrrrrrr}
\hline & \multicolumn{2}{c}{ Avg. Monthly Peak Vehicles } & \multicolumn{3}{c}{ Avg. Monthly Veh Miles } \\
& \multicolumn{1}{c}{ Pre } & \multicolumn{1}{c}{ Post } & \multicolumn{1}{c}{ \% Chg } & \multicolumn{1}{c}{ Pre } & \multicolumn{1}{c}{ Post } & \% Chg \\
Administrative Salary* & $\$ 512.30$ & $\$ 512.20$ & $-0.02 \%$ & $\$ 0.241$ & $\$ 0.259$ & $7.48 \%$ \\
Driver Salary & $\$ 1,843.80$ & $\$ 1,864.00$ & $1.10 \%$ & $\$ 0.868$ & $\$ 0.943$ & $8.68 \%$ \\
Dispatch Salary & $\$ 434.60$ & $\$ 418.60$ & $-3.68 \%$ & $\$ 0.205$ & $\$ 0.212$ & $3.55 \%$ \\
Driver \& Disp Salary & $\$ 2,278.40$ & $\$ 2,282.60$ & $0.18 \%$ & $\$ 1.072$ & $\$ 1.155$ & $7.70 \%$ \\
Total Salary & $\$ 2,887.20$ & $\$ 2,893.55$ & $0.22 \%$ & $\$ 1.359$ & $\$ 1.464$ & $7.74 \%$ \\
Salary \& Oper Exp & $\$ 4,075.25$ & $\$ 4,050.50$ & $-0.61 \%$ & $\$ 1.918$ & $\$ 2.049$ & $6.85 \%$ \\
Total Expenses & $\$ 5,006.95$ & $\$ 5,170.45$ & $3.27 \%$ & $\$ 2.356$ & $\$ 2.616$ & $11.01 \%$ \\
Vehicle Hours & 164.35 & 159.40 & $-3.01 \%$ & 0.077 & 0.081 & $4.26 \%$ \\
\hline
\end{tabular}

Source: Pagano et al., 2000. * All financial data are averages of six-month pre- and post-implementation periods; non-financial data are averages of a two-month period from both the pre- and post-implementation periods.

The first set of columns in Table 4 show efficiency measures per average peak vehicle in the pre- and post-implementation periods. Because average peak vehicles remained constant between the two periods, the peak vehicle column shows only the relative difference between the respective financial variable in each row. Salaries, except for dispatch salaries, were relatively stable between the two periods. Salary and operating expenses fell slightly. Total expenses per peak-period vehicle grew 3.3\%, due to nonCASD related factors. Vehicle hours per peak vehicle fell 3 percent. increase (from 34 to 34.5) in employees (Table 3) along with small expense gains overall coupled with reductions in dispatch and operating expenses (Table 2) underlies the negative changes in financial to employee ratios in Table 4.

Table 5 displays the relationship between salary variables, one-way passenger trips, and vehicle hours. The minimal gains and small negative changes in salary components are overwhelmed by the $6.5 \%$ decrease in passenger trips. The decrease in passenger trips, unrelated to CASD implementation, caused all salary to passenger trip ratios to have relatively significant increases.

Table 5: Average Monthly Efficiency Measures Matrix 2 (before-after analysis)

\begin{tabular}{lcccccc}
\hline & \multicolumn{2}{c}{ Avg. One-Way Pass Trips } & \multicolumn{3}{c}{ Avg. Monthly Veh Hours } \\
& Pre & $\underline{\text { Post }}$ & \multicolumn{1}{c}{$\%$ Chg } & \multicolumn{1}{c}{ Pre } & \multicolumn{1}{c}{ Post } & \multicolumn{1}{c}{$\%$ Chg } \\
Administrative Salary* & $\$ 0.869$ & $\$ 0.929$ & $6.98 \%$ & $\$ 3.117$ & $\$ 3.213$ & $3.09 \%$ \\
Driver Salary & $\$ 3.127$ & $\$ 3.383$ & $8.18 \%$ & $\$ 11.219$ & $\$ 11.694$ & $4.23 \%$ \\
Dispatch Salary & $\$ 0.737$ & $\$ 0.760$ & $3.07 \%$ & $\$ 2.644$ & $\$ 2.626$ & $-0.69 \%$ \\
Driver \& Disp Salary & $\$ 3.864$ & $\$ 4.142$ & $7.20 \%$ & $\$ 13.863$ & $\$ 14.320$ & $3.30 \%$ \\
Total Salary & $\$ 4.896$ & $\$ 5.251$ & $7.24 \%$ & $\$ 17.567$ & $\$ 18.153$ & $3.33 \%$ \\
Salary \& Oper Exp & $\$ 6.911$ & $\$ 7.351$ & $6.35 \%$ & $\$ 24.796$ & $\$ 25.411$ & $2.48 \%$ \\
Total Expenses & $\$ 8.491$ & $\$ 9.383$ & $10.50 \%$ & $\$ 30.465$ & $\$ 32.437$ & $6.47 \%$ \\
Vehicle Miles & 3.604 & 3.587 & $-0.46 \%$ & 12.929 & 12.400 & $-4.09 \%$ \\
\hline Source: Pagano et al., 2000. * All financial data are averages of six-month pre- and post-implementation periods; \\
non-financial data are averages of a two-month period from both the pre- and post-implementation periods.
\end{tabular}


A drop in vehicle hours, also related to a decline in ridership, produced an overall increase in salary-to-vehicle-hour ratios. The decrease in both vehicle miles and vehicle hours caused a slight decrease in average speed from nearly 13 to just over 12 miles per hour.

A decrease in miles per hour in this case is an ambiguous indicator, in that changes in ridership demographics (disabilities, traffic patterns, etc) all impact how quickly the vehicles move from point to point. Average speed decreases can also be a negative quality indicator, and in this case corresponds to a calculated mean ride time increase per passenger ride of approximately one minute.

The before-and-after efficiency analysis results are not encouraging. On this basis, little efficiency gains and some efficiency losses seem to have resulted from the CASD system implementation.

\section{Before-and-After Effectiveness Analysis}

Examination of salary to passenger-related ratios provide a sense of how inputs are related to system outputs. The lower the ratio, the more effectively the system is distributing its outputs. Table 6 shows the results of the small changes in salaries and wages and larger decreases in one-way passenger trips between the pre and post-implementation periods. The greater decline in passenger trips drives all salary per passenger trip ratios upward. The similar magnitude of change in dispatcher salary and passenger hours results in a near zero change in that ratio, showing that on average, one dollar of dispatcher time is invested for each hour of passenger time in both the pre- and post-implementation periods.

Vehicle miles per passenger trip changed imperceptibly, from 3.60 miles per passenger trip to 3.59 miles per trip (Table 6). The negligible change in this measure is the result of similar reductions in both passenger trips and vehicle miles (Table 3). Reductions in this measure would have been expected as a result of route optimization algorithms. However, incomplete implementation of this feature prevented accurate assessment of this feature's impact.

Overall effectiveness measures have declined between the pre- and postimplementation periods as a result of the measure's underlying linkage with ridership levels that have declined due to non-CASD related reasons (vehicle productivity, measured by passenger trips per vehicle hour, declined from 3.59 to 3.46 in Table 6, row 6, columns 7 and 8). This reflects the reduction in passenger trips on overall effectiveness of the system.

\section{With-and-Without Efficiency Analysis}

A with-and-without efficiency and effectiveness analysis was conducted that filters out changes that are not directly related to the CASD implementation. In this context, the following variables would remain unchanged between the without CASD and

Table 6: Average Monthly Effectiveness Measures Matrix (before-after analysis)

\begin{tabular}{|c|c|c|c|c|c|c|c|c|c|}
\hline & \multicolumn{3}{|c|}{ One-way Pass Trips } & \multicolumn{3}{|c|}{ Passenger Hours } & \multicolumn{3}{|c|}{ Vehicle Hours } \\
\hline & Pre & $\underline{\text { Post }}$ & \%Chg & Pre & Post & \%Chg & Pre & Post & \% Chg \\
\hline Admin Salary* & $\$ 0.869$ & $\$ 0.929$ & $6.98 \%$ & $\$ 1.229$ & $\$ 1.276$ & $3.82 \%$ & $\$ 3.117$ & $\$ 3.213$ & $3.09 \%$ \\
\hline Driver Salary & $\$ 3.127$ & $\$ 3.383$ & $8.18 \%$ & $\$ 4.425$ & $\$ 4.645$ & $4.98 \%$ & $\$ 11.219$ & $\$ 11.694$ & $4.23 \%$ \\
\hline Dispatch Salary & $\$ 0.737$ & $\$ 0.760$ & $3.07 \%$ & $\$ 1.043$ & $\$ 1.043$ & $0.01 \%$ & $\$ 2.644$ & $\$ 2.626$ & $-0.69 \%$ \\
\hline Total Salary & $\$ 4.896$ & $\$ 5.251$ & $7.24 \%$ & $\$ 6.929$ & $\$ 7.210$ & $4.07 \%$ & $\$ 17.567$ & $\$ 18.153$ & $3.33 \%$ \\
\hline Total Expenses & $\$ 8.491$ & $\$ 9.383$ & $10.50 \%$ & $\$ 12.016$ & $\$ 12.884$ & $7.23 \%$ & $\$ 30.465$ & $\$ 32.437$ & $6.47 \%$ \\
\hline One-way Pass Trips & - & - & - & 1.415 & 1.373 & $-2.96 \%$ & 3.588 & 3.457 & $-3.64 \%$ \\
\hline Vehicle Miles & 3.604 & 3.587 & $-0.46 \%$ & 5.099 & 4.925 & $-3.41 \%$ & 12.929 & 12.400 & $-4.09 \%$ \\
\hline
\end{tabular}

Source: Pagano et al., 2000. * All financial data are averages of six-month pre- and post-implementation periods; non-financial data are averages of a two-month period from both the pre- and post-implementation periods. 
with CASD periods: driver, dispatch and maintenance salaries (taking into account any additional personnel not associated with CASD implementation ${ }^{1}$ ), one-way passenger trips, passenger hours, peak vehicles, and vehicle miles and hours, as shown in Tables 7 and 8. As explained earlier, driver, dispatcher, and maintenance salary changes could not be linked to CASD implementation. Similarly, changes in one-way passenger trips and related vehicle hours and miles were the result of contractual changes ${ }^{1}$.
Clearly noticeable improvements are now observed in every efficiency measure in Tables 9 and 10 . Notice, for example, the $2.18 \%$ drop in salary and operating expenses in Tables 9 and 10. This improvement, given approximately a $\$ 4,000$ monthly expense per vehicle (Table 9) and, on average, 20 peak vehicles (Table 8), would translate to savings of more than $\$ 20,000$ per year (note that $\$ 88.65$ savings per vehicle per month multiplied by 20 vehicles multiplied by 12 months is $\$ 21,276$ ).

Table 7: Average Monthly Financial Variables (with-without analysis)

\begin{tabular}{|c|c|c|c|c|}
\hline $\begin{array}{c}\text { Category } \\
\text { (Average Monthly) }\end{array}$ & $\begin{array}{l}\text { Without CASD } \\
\text { (Avg. Monthly) }\end{array}$ & $\begin{array}{l}\text { With CASD } \\
\text { (Avg. Monthly) }\end{array}$ & $\begin{array}{l}\text { Avg. Monthly } \\
\text { With CASD } \\
\text { (Less CPI and Adt'l } \\
\text { Pers) }\end{array}$ & $\begin{array}{c}\text { With-Without Adj. } \\
\text { \% Change** }\end{array}$ \\
\hline Administrative Salary & $\$ 10,246$ & $\$ 11,780$ & $\$ 10,244$ & $-0.02 \%$ \\
\hline Driver Salaries & $\$ 36,876$ & $\$ 36,876$ & $\$ 36,089$ & $-2.13 \%$ \\
\hline Dispatch Salaries & $\$ 8,692$ & $\$ 8,554$ & $\$ 8,372$ & $-3.69 \%$ \\
\hline Maintenance Salaries & $\$ 1,930$ & $\$ 1,930$ & $\$ 1,975$ & $-2.13 \%$ \\
\hline Total Salary & $\$ 57,744$ & $\$ 59,140$ & $\$ 56,593$ & $-1.99 \%$ \\
\hline Operating Expenses* & $\$ 23,761$ & $\$ 23,644$ & $\$ 23,139$ & $-2.62 \%$ \\
\hline Other Costs & $\$ 18,634$ & $\$ 22,888$ & $\$ 22,399$ & $20.21 \%$ \\
\hline Total Costs & $\$ 100,139$ & $\$ 105,672$ & $\$ 102,131$ & $1.99 \%$ \\
\hline
\end{tabular}

Table 8: Average Monthly Weekday Non-Financial Measures (with-without analysis)

\begin{tabular}{lcccc}
\hline $\begin{array}{c}\text { Category } \\
\text { (Average Monthly Mon. - Fri) }\end{array}$ & $\begin{array}{c}\text { Without } \\
\text { CASD } \\
\text { (Avg. Mo.) }\end{array}$ & $\begin{array}{c}\text { With CASD } \\
\text { (Avg. Mo.) }\end{array}$ & $\begin{array}{c}\text { With CASD } \\
\text { Adjusted } \\
\text { (Avg. Monthly less- } \\
\text { Adt'l Pers) }\end{array}$ & $\begin{array}{c}\text { With- } \\
\text { Without } \\
\text { Adj. } \\
\text { \% Change }\end{array}$ \\
\hline Employees & 34 & 37 & 34.5 & $1.47 \%$ \\
Passenger Hours & 8,334 & 8,334 & - & $0.00 \%$ \\
One-Way Passenger Trips & 11,793 & 11,793 & - & $0.00 \%$ \\
Peak Vehicles (Avg. Weekday) & 20 & 20 & - & $0.00 \%$ \\
Vehicle Hours & 3,287 & 3,287 & - & $0.00 \%$ \\
Vehicle Miles & 42,498 & 42,498 & - & $0.00 \%$ \\
\hline Dan
\end{tabular}

Data source: Pagano et al., 2000. 
Table 9: Average Monthly Efficiency Measures Matrix (with-without analysis)

\begin{tabular}{|c|c|c|c|c|c|c|}
\hline & \multicolumn{3}{|c|}{ Avg. Monthly Peak Vehicles } & \multicolumn{3}{|c|}{ Avg. Monthly Veh Miles } \\
\hline & $\begin{array}{l}\text { Without } \\
\text { CASD }\end{array}$ & $\begin{array}{l}\text { With } \\
\text { CASD }\end{array}$ & \% Chg & $\begin{array}{l}\text { Without } \\
\text { CASD }\end{array}$ & $\begin{array}{l}\text { With } \\
\text { CASD }\end{array}$ & \% Chg \\
\hline Administrative Salary* & $\$ 512.30$ & $\$ 512.20$ & $-0.02 \%$ & $\$ 0.241$ & $\$ 0.241$ & $7.5 \%$ \\
\hline Driver Salary & $\$ 1,843.80$ & $\$ 1,804.44$ & $-2.13 \%$ & $\$ 0.868$ & $\$ 0.849$ & $3.5 \%$ \\
\hline Dispatch Salary & $\$ 434.60$ & $\$ 418.57$ & $-3.69 \%$ & $\$ 0.205$ & $\$ 0.197$ & $8.7 \%$ \\
\hline Driver \& Disp Salary & $\$ 2,278.40$ & $\$ 2,223.01$ & $-2.43 \%$ & $\$ 1.072$ & $\$ 1.046$ & $7.7 \%$ \\
\hline Total Salary & $\$ 2,887.20$ & $\$ 2,829.65$ & $-1.99 \%$ & $\$ 1.359$ & $\$ 1.332$ & $7.7 \%$ \\
\hline Salary \& Oper Exp & $\$ 4,075.25$ & $\$ 3,986.60$ & $-2.18 \%$ & $\$ 1.918$ & $\$ 1.876$ & $6.8 \%$ \\
\hline Total Expenses & $\$ 5,006.95$ & $\$ 5,106.55$ & $1.99 \%$ & $\$ 2.356$ & $\$ 2.403$ & $11.0 \%$ \\
\hline
\end{tabular}

Table 10: Average Monthly Efficiency Measures Matrix 2 (with-without analysis)

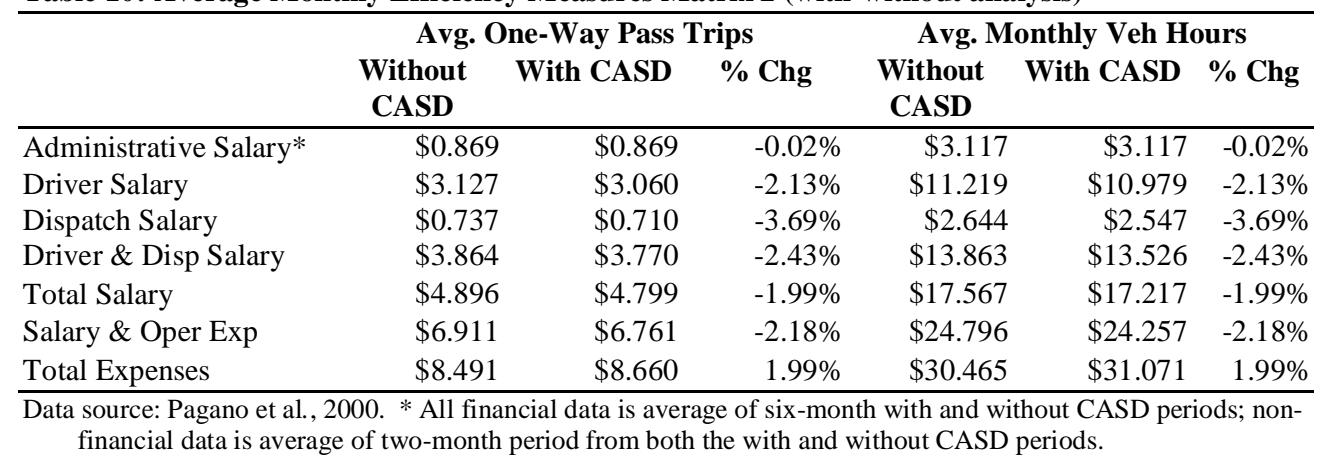

\section{With-and-Without Effectiveness Analysis}

The previous before-and-after effectiveness analysis shows that the CASD impacts on operations had mixed results and would probably require a much longer time frame to take effect than the six-month observation period reported. In a similar manner as above, a with-and-without analysis that filters out changes that are not directly related to the CASD implementation was conducted holding constant the same variables as before. The results from this exercise are shown in Table 11. Clearly the implementation of the CASD system has brought a small but measurable increase in effectiveness as measured by the proposed effectiveness measures.

Table 11: Average Monthly Effectiveness Measures Matrix (with-without analysis)

\begin{tabular}{|c|c|c|c|c|c|c|c|c|c|}
\hline & \multicolumn{3}{|c|}{ One-way Pass Trips } & \multicolumn{3}{|c|}{ Passenger Hours } & \multicolumn{3}{|c|}{ Vehicle Hours } \\
\hline & $\begin{array}{l}\text { Without } \\
\text { CASD }\end{array}$ & $\begin{array}{l}\text { With } \\
\text { CASD }\end{array}$ & \% Chg & $\begin{array}{l}\text { Without } \\
\text { CASD }\end{array}$ & $\begin{array}{l}\text { With } \\
\text { CASD }\end{array}$ & \% Chg & $\begin{array}{l}\text { Without } \\
\text { CASD }\end{array}$ & $\begin{array}{l}\text { With } \\
\text { CASD }\end{array}$ & \% Chg \\
\hline Admin Salary* & $\$ 0.869$ & $\$ 0.869$ & $-0.02 \%$ & $\$ 1.229$ & $\$ 1.229$ & $-0.02 \%$ & $\$ 3.117$ & $\$ 3.117$ & $-0.02 \%$ \\
\hline Driver Salary & $\$ 3.127$ & $\$ 3.060$ & $-2.13 \%$ & $\$ 4.425$ & $\$ 4.330$ & $-2.13 \%$ & $\$ 11.219$ & $\$ 10.979$ & $-2.13 \%$ \\
\hline Dispatch Salary & $\$ 0.737$ & $\$ 0.710$ & $-3.69 \%$ & $\$ 1.043$ & $\$ 1.004$ & $-3.69 \%$ & $\$ 2.644$ & $\$ 2.547$ & $-3.69 \%$ \\
\hline Total Salary & $\$ 4.896$ & $\$ 4.799$ & $-1.99 \%$ & $\$ 6.929$ & $\$ 6.791$ & $-1.99 \%$ & $\$ 17.567$ & $\$ 17.217$ & $-1.99 \%$ \\
\hline Total Expenses & $\$ 8.491$ & $\$ 8.660$ & $1.99 \%$ & $\$ 12.016$ & $\$ 12.255$ & $1.99 \%$ & $\$ 30.465$ & $\$ 31.071$ & $1.99 \%$ \\
\hline
\end{tabular}




\section{CONCLUSIONS}

In times of constrained transit budgets, the need to provide efficient and effective transportation services has never been greater. Ensuring the best possible future for this market means learning now how to use information to improve the performance of vehicles, agency operations, and interaction with riders.

The previous discussion reported on a comprehensive evaluation of a CASD system in a small rural transportation agency in central
Illinois. The results confirm expectations from previous work that CASD systems have the potential to improve the efficiency and effectiveness aspects of transit operations even in small rural agencies.

This paper also provides an important lesson for future evaluation efforts of CASD systems. Such studies should allow enough time after implementation so that not only familiarity with the system has been established, but also most or all of the necessary organizational changes related to the new technology have been completed.

\section{Endnotes}

Pre- and post-implementation employee levels changed with the addition of a full-time operations manager, and one full-time and one part-time maintenance employee. One additional part-time employee has been added to assist in run posting, augmenting permanent staff when needed. The operations manager position was added as a result of a change in the transit district's contract requirements, while maintenance personnel were added to assist an already over-taxed maintenance staff. No direct or indirect CASD influences were observed in the operations manager or maintenance personnel additions. The part-time run-posting position is a direct result of CASD implementation, reflecting the added task of updating the CASD database with every passenger manifest. CASD operations require run-posting activities to update projected database arrival/departure times, passenger loading, no-shows, etc. Additionally, during the course of the evaluation, contractual service agreements between the paratransit operator and some of its clients changed affecting some measures (e.g., ridership, vehicle hours, etc.).

\section{References}

Allen W. G. and F. DiCesare. “Transit Service Evaluation: Preliminary Identification of Variables Characterizing Level of Service.” Transportation Research Record, 606, (1976): 41-47.

Casey, R. F. and F. Collura. Advanced Public Transportation Systems: Evaluation Guidelines. Report No. DOT-T-94-10. Federal Transit Administration, 1994.

Goeddel, Dennis L. Benefits Assessment of Advanced Public Transportation Systems. Report No. DOTVNTSC-FTA-96-7. Volpe Transportation Systems Center, 1996.

Goeddel, Dennis L. Benefits Assessment of Advanced Public Transportation System Technologies Update 2000. Report No. DOT-VNTSC-FTA-00-2. Volpe Transportation Systems Center, 2000.

Khattak, A. and M. Hickman. “Automatic Vehicle Location and Computer Assisted Dispatch Systems: Design and Application Considerations.” Journal of Public Transportation 2 (1), (1998): 1-26.

Kikuchi, Shinya. "Development of Computerized Vehicle Scheduling System for Specialized Transportation: Delaware Case.” Transportation Planning and Technology 12, (1988): 151-170.

Lave, R. M., R. Teal, and P. Piras. Handbook for Acquiring Demand Responsive Transit Software. TCRP Report 18, 1996.

Pagano, A. M., C. McKnight, and M. Dichter-Figurera. Quality of Service in Special Transportation for the Elderly and Handicapped. Report No: UMTA-IL-11-0028-83-2, 1983. 
Pagano, A.M., P. Metaxatos, and M. King. Computer-Aided Scheduling and Dispatching System: Impacts on Operations and Coordination. Report No. ITRC-FR 98-3, 2000. Illinois Department of Transportation: Illinois Transportation Research Center, 2000.

Pagano, A.M., P. Metaxatos, and M. King. "How Effective is Computer-Assisted Scheduling and Dispatching in Paratransit? Results from a Survey.” Transportation Research Record, 1760, (2001): 100-106.

Pagano, A.M., P. Metaxatos and M. King (2002). "Effect of Computer-Assisted Scheduling and Dispatching Systems on Paratransit Service Quality.” Transportation Research Record 1791, (2002): 51-58.

Stone, J.R., A.M. Nalevanko, and G. Gilbert. "Computer Dispatch and Scheduling for Paratransit: An Application of Advanced Public Transportation Systems.” Transportation Quarterly 48 (2), (1994): 173184.

Stone, J.R., J.W. Baugh, S. Chakravarty, and M.N. Surasky. "Winston-Salem Mobility Manager: Data Collection, Validation, and Performance Evaluation.” Transportation Research Record, 1760, (2001): 114-120.

Tomazinis, Anthony R. Productivity, Efficiency, and Quality in Urban Transportation Systems. DC Heath and Co., Lexington MA, 1975.

Underwood, S., J. Levine, R. Wallace, and T. B. Reed. SMART APTS Operational Field Test Evaluation Plan. An Evaluation of the Suburban Mobility Authority for Regional Transportation's Advanced Public Transportation System's Project. University of Michigan Intelligent Transportation Systems, Ann Arbor MI, 1995.

Urban Transportation Glossary, ed. Gray, B. H. Transportation Research Board, National Research Council. Washington, D.C, 1989.

\section{Acknowledgements}

The authors wish to thank the anonymous referees for helpful comments. The authors also acknowledge the financial support from the Illinois Department of Transportation under grant IVA-H1, FY 98.

Dr. Paul Metaxatos is research assistant professor in the Urban Transportation Center of the University of Illinois at Chicago. He received his doctorate in public policy analysis and his master's in geography from the University of Illinois at Chicago, and a B.S. in rural and surveying engineering from the National Technical University of Athens, Greece. He has conducted research on transit and transit operations planning, evaluation of intelligent transportation systems, freight planning, and transportation modeling.

Anthony M. Pagano is associate professor of management at the University of Illinois at Chicago and adjunt professor of management and strategy, J.L. Kellogg Graduate School of Management, Northwestern University. The author or coauthor of more than 100 articles, technical reports, and papers presented at professional meetings, he is the coauthor of the textbook The External Environment of Business: Political Economic, Social and Regulatory, Stipes Publishing Co., Champaign, IL, 1995, 2nd ed 1997. (with JoAnn Verdin) He has been project director or project manager of over 30 separate research and consulting projects. He also served as cofounder and co-general editor of the Journal of the Transportation Research Forum. He teaches courses in transportation management, economics and public policy. He has a Ph.D. in economics from the Pennsylvania State University. 